\title{
Chronic obstructive pulmonary disease patients and steroids: benefit or harm
}

\author{
Abdul Hamid Khan ${ }^{1}$, Mehwish Majeed ${ }^{2} *$
}

${ }^{1}$ Consultant Physician at SDH Sopore, Jammu \& Kashmir, India

${ }^{2}$ Department of Clinical Pharmacology, SKIMS, Soura, Srinagar, Jammu \& Kashmir, India

Received: 12 July 2019

Revised: 16 September 2019

Accepted: 17 September 2019

*Correspondence to:

Dr. Mehwish Majeed,

Email: mehwishmajeed10

@gmail.com

Copyright: (C) the author(s), publisher and licensee Medip Academy. This is an openaccess article distributed under the terms of the Creative Commons Attribution NonCommercial License, which permits unrestricted noncommercial use, distribution, and reproduction in any medium, provided the original work is properly cited.

\begin{abstract}
Background: Corticosteroids are being widely used in conditions related to allergy and inflammation. There are great species differences in the responses to glucocorticoids that mean a "steroid resistant" species. Steroids have profound effect on inflammatory response by way of vasoconstriction, decreased chemotaxis and interference with macrophages. There still are enormous gaps in our knowledge of the action of glucocorticosteroids in patients of chronic obstructive lung disease (COPD).

Methods: This study was done in the department of general medicine at SKIMS, Srinagar from December 2017 to December 2018 on patients of chronic obstructive pulmonary disease. A total number of 100 patients were enrolled for the study but 20 patients, 10 from each group lost their follow up. To see the effect of steroids on pulmonary function tests, patients were divided into case and control group. Patients in case group were given prednisolone 30 $\mathrm{mg}$ orally for two week (tapering dose). Patients in control group were given placebo for the same duration of two weeks. Steroid response was defined as $15 \%$ improvement in baseline forced expiratory volume (FEV).

Results: Steroid response was defined as $15 \%$ increase in forced expiratory volume in one second/forced vital capacity (FEV1/FVC) after receiving tapering dose of prednisone $30 \mathrm{mg}$ for 2 weeks, no patients in case group showed increase in FEV1/FVC of $15 \%$. The change in pulmonary function tests was comparable in each group $(\mathrm{p}>0.5)$.

Conclusions: The change in pulmonary function tests were comparable in each group ( $>0.5$ ). So, steroids in stable patients of COPD are best to be avoided.
\end{abstract}

Keywords: Chronic obstructive lung disease, Steroids, FVC, FEV1

\section{INTRODUCTION}

Chronic obstructive lung disease (COPD) is one of the leading causes of death worldwide, with an estimated prevalence of almost $11 \%$ in adults aged $\geq 38$ years. ${ }^{1}$ Chronic obstructive disease has been defined by the American Thoracic Society as a disease state characterized by the presence of air flow obstruction secondary to chronic bronchitis or emphysema. ${ }^{2}$ Chronic bronchitis is defined for epidemiologic purposes as the presence of chronic cough for 3 months in each 2 successive years. Conditions like mycobacterial tuberculosis, carcinoma of lung or congestive failure have been excluded. ${ }^{2}$ Emphysema on the other hand is defined pathologically as abnormal air space enlargement. ${ }^{3,4}$

\section{COPD history}

Forced expiratory volume in one second (FEV1) decreases around $90 \mathrm{ml}$ a year in COPD patients. Patients who stopped smoking had a mean post bronchodilator FEV1 increase of $57 \mathrm{ml}$ at first annual visit compared 
with a mean FEV1 decline of $38 \mathrm{ml}$ for those who continue to smoke as shown by Lung Heath Study.,

\section{Pathology}

Chronic bronchitis is associated with hypertrophy of mucus producing glands found in the submucosal of large cartilaginous airways. In lungs from patients with chronic obstructive lung disease which have been studied at postmortem, the major site of airflow obstruction has been shown to be in the small airways. Goblet cell hyperplasia, mucosal and submucosal inflammatory cells, edema peri bronchial fibrosis, intraluminal mucus plugs and increased smooth muscle are characteristic finding in small airways. It is the consequence of the action of interleukin-8 and a variety of other chemotactic and proinflammatory cytokines. Chronic bronchitis is characterized pathologically by hypertrophy of submucin glands found in submucosa of lung cartilaginous airways; which is indicated by reid index. ${ }^{7-9}$ Normal Reid index (RI) is 0.44. Patients with COPD have a RI of 0.52 . Emphysema has two types such as centriacunar and panacinar

Centriacinar emphysema characterized by distention and destruction limited to respiratory bronchioles with less changes in the periphery of acirus whereas in panacinar emphysema both central and peripheral portions of lungs are involved. ${ }^{3,10}$

\section{Pulmonary function tests}

Roughly comparable information can be obtained from the peak flow measurement or from the forced expiratory flow volume level. None of these tests can distinguish between chronic bronchitis and emphysema. ${ }^{2,3,11,12}$

The FEV and forced expiratory volume in one second/forced vital capacity (FEV/FVC) ratio fall progressively as the severity of COPD increases. In the laboratory about $30 \%$ of patients have an increase of $20 \%$ or more in their FEV, following a $\beta$-agonist, ipratropium bromide treatment. Lung volume measurements show an increase in total lungs capacity, functional residual capacity and residual volume. The vital capacity may be decreased.

\section{Management of patients with COPD}

Management of patients with COPD includes smoking cessation, pharmacological therapy and vaccination. ${ }^{13-16}$ The different drugs used in management of COPD using pharmacological therapy are: (a) bronchodilators which consists of three types such as $\beta$-agonists, anticholinergic drugs, methylxanthines and (b) corticosteroides. ${ }^{1,7,17-21}$

\section{Mechanism of action of steroids}

Steroids affect metabolism and distribution of $\mathrm{T}$ and $\mathrm{B}$ lymphocytes, but do not significantly affect antibody production in man. Steroids profoundly affect the inflammatory response by way of vasoconstriction, decreased chemotaxis and interference with macrophages. Steroids affect type I, III and IV mechanisms of immunologic injury. There are still enormous gaps in our knowledge of the action of glucocorticosteroids. Studies done by Fan et al showed that use of oral steroids showed no differences in rates of re-hospitalization. ${ }^{18}$

In a meta-analysis of all English language placebo controlled trials of oral steroids in COPD published between 1966 and 1989, 10 studies met nine prospectively defined standard. The response to oral corticosteroids was defined as $20 \%$ improvement in base FEV, and the number of patients who responded was separated from those who responded to placebo. Overall $10 \%$ of patients fulfilled the criteria for response. No association was found between corticosteroid response and clinical features such as age or baseline FEV1. The use of inhaled corticosteroids in COPD patients holds some promise but at present has not been demonstrated conclusively. Studies have shown that patients receiving oral corticosteroids have a $20 \%$ or greater increase in FEV1, only $10 \%$ more often than patients receiving placebo. Long term systemic glucocorticoid use is associated with worsened osteoporosis and increased risk of vertebral fracture.

There is lack of knowledge with regards to the action of glucocorticosteroids in patients of COPD. Thus this study was undertaken to find out the effect of steroids on pulmonary function in stable patients of chronic obstructive pulmonary disease and to know the clinical improvement in such patients by giving steroids.

\section{Objectives}

The main objective of this study is to find out the effect of steroids on pulmonary function in stable patients of chronic obstructive pulmonary disease and to know the clinical improvement in such patients by giving steroids.

\section{METHODS}

This study was done in the department of General Medicine at SKIMS, Srinagar from December 2017 to December 2018 on patients of chronic obstructive pulmonary disease. A total number of 100 patients were enrolled for the study but 20 patients, 10 from each group lost their follow up.

In this study, the total number of patients who completed the study was 40 in each group. Out of 40 patients, 28 were males and 12 were females (Table 1).

Patients who were following the General Medicine Department at SKIMS, Srinagar with inclusion criteria such as previous diagnosis of COPD based on American Thoracic Society definition, onset of respiratory difficulty 
after the age of 30 years, respiratory symptom (dyspnea, cough and sputum production) ) for greater than 5 years, patients without an exacerbation of COPD, no known allergy or history of asthma (personal or family), no overt evidence of cardiac decompensation and no steroid treatment for at least one month before entrance into the study were included .

To see the effect of steroids on pulmonary function tests patients were divided into case and control group. Patients in case group were gives prednisolone $30 \mathrm{mg}$ orally for two week (tapering dose). Patients in control group were given placebo for the same duration of two weeks. Steroid response was defined as $15 \%$ improvement in baseline FEV.

\section{Statistical analysis}

The characteristics of all treatment groups were compared for both demographic and efficacy variables. Data were expressed as mean \pm standard error mean (SEM). The values of symptom score for each group were anlysed by ANOVA followed by Turkey`s test. Comparison was made between baseline and post treatment after two weeks between treatment groups. $\mathrm{P}<0.05$ was considered as significant.

\section{RESULTS}

This study was done in the department of General Medicine at SKIMS, Srinagar from December 2017 to December 2018 on patients of chronic obstructive pulmonary disease. A total number of 100 patients were enrolled for the study, but 20 patients, 10 from control and 10 from case group lost their follow up.

In this study, the total number of patients who completed the study was 40 in each group. Out of 40 patients, 28 were males and 12 were females (Table 1).

The mean age was 61.93 years (range 52-80) in case group and 61.98 years (52-75) in control group. However, the age of the two groups was comparable $(\mathrm{p}>0.05)$ (Table 1).
In this study we found bilateral rhonchi on chest auscultation as the commonest clinical sign, which was present in 34 patients from case group and 37 of patients from control group.

Cyanosis was present in 6 patients in case group and 7 patients in control group. Loud P2 suggestive of pulmonary arterial hypertension was present in 6 patients in case group and 2 patients from control group (Figure 1).

The chest radiographic evidence of hyper inflated lung fields, suggestive of chronic obstructive pulmonary disease was present in 33 patients in case and 32 patients in control group (Figure 2).

The most common electrographic finding in both groups was P-pulmonale suggestive of right atrial hypertrophy (Figure 2).

The biochemical parameters were within the normal range in both case and control group (Table 2).

The mean haemoglobin in case group was $15.22 \mathrm{gm} \%$ and 14.99 gm\% in control group. The mean haematocrit in case group was 49.00 and 49.07 in the control group (Table 3).

The pulmonary function tests (FEV1, FVC, FEV1/FVC) in both groups were comparable before giving steroids or placebo (Table 4).

The pulmonary function tests (FEV, FVC, FEV,/FVC and percentage change in FEV, FVC, FEV /FVC) were comparable in case and control group after giving steroids and placebo respectively. The maximum percentage change in FEV1/FVC was not more than $7 \%$ in case group (Table 5).

The adverse effects consequent to steroid therapy in case group were hypertension, ulcer symptoms and hyperglycemia (Figure 3).

Table 1: Demographic profile, duration of smoking and symptom duration of case and control group.

\begin{tabular}{|c|c|c|c|}
\hline Parameter & Case group $(n=40)$ & Control group $(n=40)$ & Statistical significance \\
\hline Age (in years) $($ mean \pm SD $)$ & $61.93 \pm 5.17$ & $61.98 \pm 5.49$ & $\mathrm{P}>0.05$ \\
\hline \multicolumn{4}{|l|}{ Sex, N (\%) } \\
\hline Male & $28(70)$ & $28(70)$ & $\mathrm{P}>0.05$ \\
\hline Female & $12(13)$ & $12(13)$ & $\mathrm{P}>0.05$ \\
\hline $\begin{array}{l}\text { Duration of smoking } \\
\text { (in years) }(\text { mean } \pm \text { SD) }\end{array}$ & $14.35 \pm 14.96$ & $18.05 \pm 14.05$ & $\mathrm{P}>0.05$ \\
\hline $\begin{array}{l}\text { Duration of symptoms } \\
\text { (in years) }(\text { mean } \pm \text { SD) }\end{array}$ & $10.00 \pm 3.66$ & $9.00 \pm 3.13$ & $\mathrm{P}>0.05$ \\
\hline
\end{tabular}

The age, sex, duration of smoking and symptoms of case and control group were comparable ( $\mathrm{p}>0.05)$. 
Table 2: Biochemical parameters of case and control group.

\begin{tabular}{|llll|}
\hline Parameter & $\begin{array}{l}\text { Case group }(\mathbf{n = 4 0}) \\
(\mathbf{m e a n} \pm \mathbf{S D})\end{array}$ & $\begin{array}{l}\text { Control group }(\mathbf{n}=\mathbf{4 0}) \\
(\text { mean } \pm \text { SD })\end{array}$ & Statistical inference \\
\hline Serum bilirubin & $0.98 \pm 0.46$ & $1.11 \pm 0.48$ & $\mathrm{P}>0.05$ \\
\hline SGOT & $30.88 \pm 6.43$ & $32.00 \pm 10.25$ & $\mathrm{P}>0.05$ \\
\hline SGPT & $32.00 \pm 7.68$ & $32.81 \pm 13.00$ & $\mathrm{P}>0.05$ \\
\hline Serum albumin & $3.43 \pm 0.31$ & $3.20 \pm 0.28$ & $\mathrm{P}>0.05$ \\
\hline Blood sugar & $84.99 \pm 11.30$ & $87.00 \pm 14.99$ & $\mathrm{P}>0.05$ \\
\hline Blood urea & $42.99 \pm 25.98$ & $4.99 \pm 36.80$ & $\mathrm{P}>0.05$ \\
\hline Serum creatinine & $1.22 \pm 0.57$ & $1.29 \pm 0.64$ & $\mathrm{P}>0.05$ \\
\hline
\end{tabular}

SGOT: Serum glutamate oxalocactate transaminase; SGPT: Serum glutamate pyruvate transaminase. The biochemical parameters in the case and control group are comparable ( $\mathrm{p}>0.05)$.

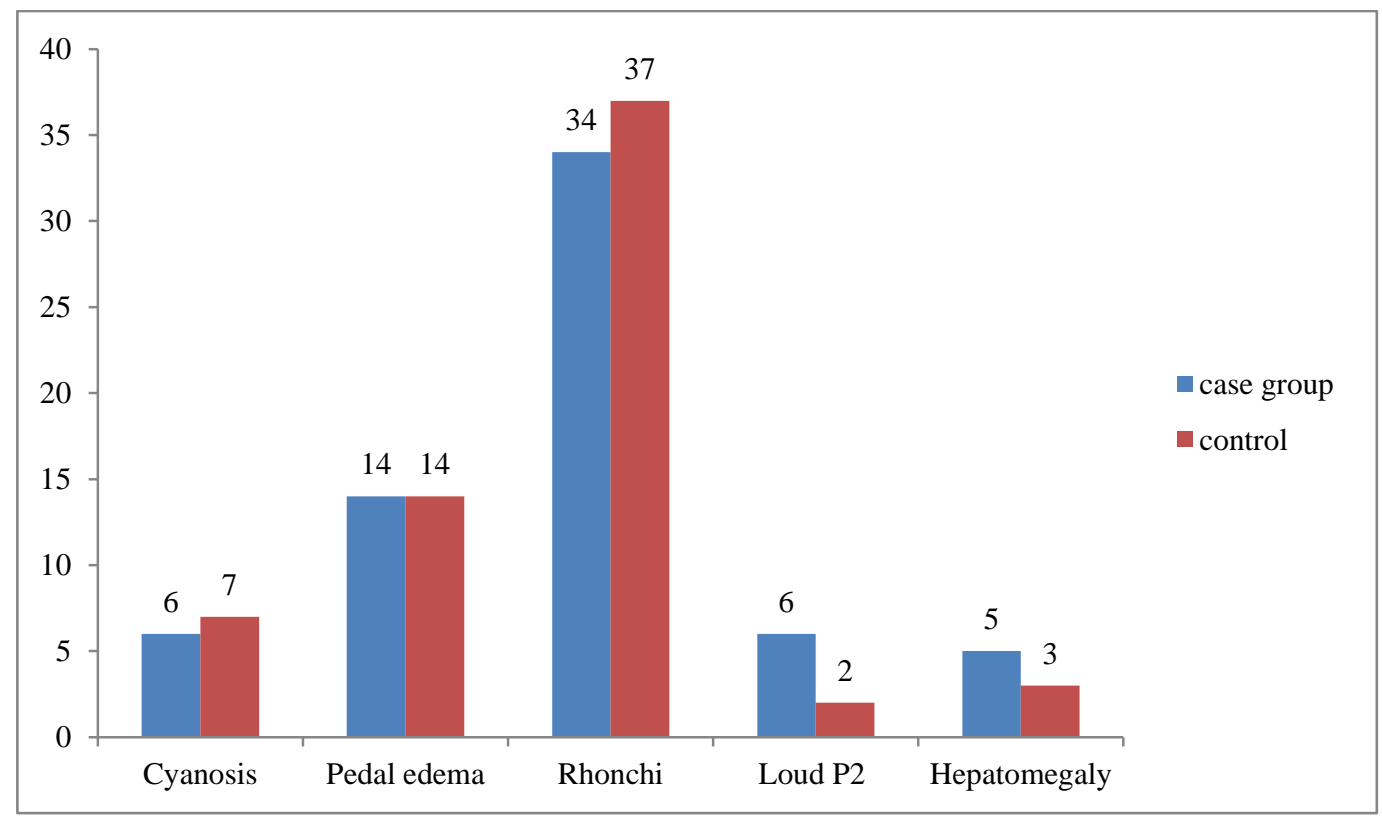

Figure 1: Clinical signs of case and control group.

The clinical signs, cyanosis pedal edema, Rhonchi, Loud P2 and hepatomegaly of case and control group were comparable (p>0.05).

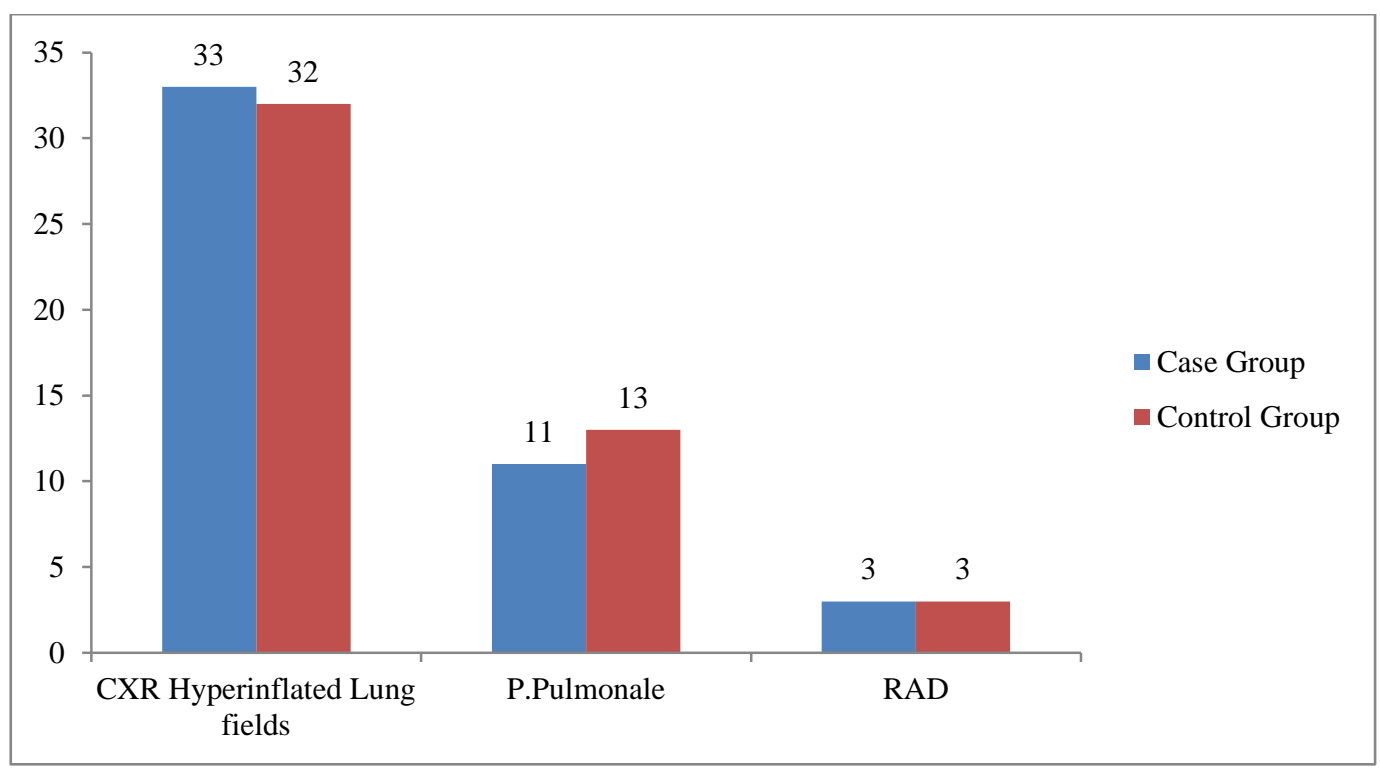

Figure 2: Radiographic and electrocardiographic parameters of case and control. 
Table 3: Hematological parameters of case and control group.

\begin{tabular}{|llll|}
\hline Parameter & Case group $(\mathbf{n}=\mathbf{4 0})$ mean \pm SD & Control group $(\mathbf{n = 4 0 )}$ mean \pm SD & Statistical inference \\
\hline Hb in gm\% & $15.22 \pm 1.01$ & $14.99 \pm 1.20$ & $\mathrm{P}>0.05$ \\
\hline TCL & $7.59 \pm 2.51$ & $6.99 \pm 1.91$ & $\mathrm{P}>0.05$ \\
\hline Polymorphs (\%) & $69.99 \pm 8.95$ & $67.00 \pm 1.93$ & $\mathrm{P}>0.05$ \\
\hline Lmphocytes (\%) & $22.00 \pm 7.63$ & $22.99 \pm 7.48$ & $\mathrm{P}>0.05$ \\
\hline Monocytes (\%) & $4.40 \pm 2.75$ & $5.00 \pm 2.74$ & $\mathrm{P}>0.05$ \\
\hline Haematocrit $(\%)$ & $49.00 \pm 3.15$ & $49.07 \pm 3.01$ & $\mathrm{P}>0.05$ \\
\hline
\end{tabular}

Hb: Haemoglobin; TLC: Total leucocyte count. Hematological parameters of case and control group were comparable ( $p>0.05)$.

Table 4: Pulmonary function tests of case and control group before steroids and placebo respectively.

\begin{tabular}{|llll|}
\hline Parameter & Case group $(\mathbf{n}=\mathbf{4 0})$ & Control group $(\mathbf{n = 4 0})$ & Statistical inference \\
\hline FEV1 $(\mathbf{L})$ mean \pm SD & $1.710 \pm 0.22$ & $1.73 \pm 0.24$ & $\mathrm{P}>0.05$ \\
\hline FVC $(\mathbf{L})$ mean \pm SD & $3.00 \pm 14.96$ & $2.87 \pm 0.31$ & $\mathrm{P}>0.05$ \\
\hline FEV1/ FVC $($ mean \pm SD) & $60.00 \pm 4.36$ & $58.99 \pm 3.99$ & $\mathrm{P}>0.05$ \\
\hline
\end{tabular}

FEV1: Forced expiratomy volume in first second; FVC: Forced vital capacity. Pulmonary function tests of case and control groups before steroids and placebo respectively were comparable $(\mathrm{p}>0.05)$.

Table 5: Pulmonary function tests of case and control group after steroids and placebo respectively.

\begin{tabular}{|llll|}
\hline Parameter & $\begin{array}{l}\text { Case group }(\mathbf{n = 4 0 )} \\
\text { Mean } \pm \text { SD }\end{array}$ & $\begin{array}{l}\text { Control group }(\mathbf{n = 4 0}) \\
\text { Mean } \pm \text { SD }\end{array}$ & \begin{tabular}{l} 
Statistical inference \\
\hline FEV1 $(\mathbf{L})$
\end{tabular} \\
\hline FVC $(\mathbf{L})$ & $2.75 \pm 0 / 184$ & $1.75 \pm 0.215$ & $\mathrm{P}>0.05$ \\
\hline FEV1 / FVC & $59.99 \pm 3.53$ & $2.71 \pm 4.36$ & $\mathrm{P}>0.05$ \\
\hline$(\%)$ age change in FEV1 & $3.11 \pm 7.52$ & $60.00 \pm 4014$ & $\mathrm{P}>0.05$ \\
\hline$(\%)$ age change in FVC & $3.20 \pm 3.63$ & $1.28 \pm 6.47$ & $\mathrm{P}>0.05$ \\
\hline$(\%)$ age change in FEV1/FVC & $1.00 \pm 5.98$ & $2.22 \pm 2.73$ & $\mathrm{P}>0.05$ \\
\hline
\end{tabular}

FEV1: Forced expiratory volume in 1st second; FVC: Forced vital capacity. (\%) age pulmonary function tests of case and control group after steroids and placebo respectively were comparable ( $p>0.05)$.

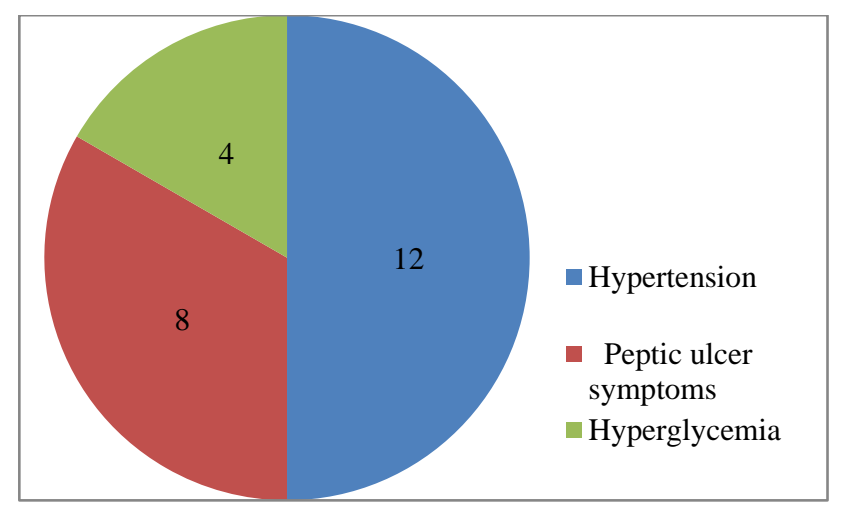

Figure 3: Steroids induced adverse effects in case group.

\section{DISCUSSION}

This study was conducted in the department of General Medicine at SKIMS, Srinagar on patients of stable chronic obstructive pulmonary disease. By stable, we meant a patient of chronic obstructive pulmonary disease documented by spirometry, which were on regular follow up without an acute exacerbation. The total number of patients who completed the study was 40 in case group and 40 in control group. In case group patients were put on prednisolone $30 \mathrm{mg}$ once a day for a period of 14 days. Pulmonary function tests were performed before and after receiving the tapering dose of prednisolone for two weeks. In control group same number of patients was given placebo for a period of two weeks and response was monitored by same tests as in case group.

In our study $80 \%$ of patients were smokers in each group with mean smoking duration of 14.35 years in case group and 18.05 years in control group. Among 32 male patients, 28 were smokers and among 12 female patients, 4 were smokers in each group. So, smoking appeared to be major risk factor for chronic obstructive pulmonary disease. A study conducted by Lowell et al in 1956 concluded that chronic obstructive disease is a disease of smokers. ${ }^{11}$ Also in the study conducted by WKC Morgan et al in 1964, all the patients were heavy smokers. Therefore, in our study it appeared that although smoking is a major risk factor for chronic obstructive pulmonary disease but other factors like environmental pollution etc also plays a role.

In our study none of 40 patients treated with prednisolone (30 mg tapering dose for 14 days) had increase in FEV1/FVC by $>15 \%$ to qualify for response. 
The maximum response was not $>6.99 \%$ increase in FEV1/FVC. This response was comparable to patients in control group where placebo was given for the same duration $(\mathrm{p}=-0.05)$ However, it was observed that $>50 \%$ patients in case group noticed subjective improvement in their symptoms probably because of the euphoriant effect of steroids. This is in agreement with the study conducted by Reidt et al who concluded that half of the patients noted subjective improvement while receiving steroids but none showed any significant change in pulmonary function tests. ${ }^{22}$ This study thus suggested that long term steroid therapy is not justified in chronic pulmonary disease.

In our study the most noticeable feature was the development of steroid related side effects in case group. More than $60 \%$ of patients developed adverse effects, when they were followed for about one month after completing 14 days course of steroids. The most common adverse effect was hypertension followed by peptic ulcer symptoms and hyperglycaemia. However none of the patients developed gastrointestinal bleeding or hyperglycaemia severe enough to warrant treatment. In previous studies hyperglycaemia was observed as major adverse effect. ${ }^{18}$

In our study, the change in pulmonary function tests post treatment in case and control group were comparable $(\mathrm{p}=-$ $0.05)$, so the role of steroids to relieve the obstruction in patients with chronic obstructive pulmonary disease has not been found to be of value. This is in agreement with most of studies conducted on patients of COPD without exacerbation.

\section{CONCLUSION}

Steroid response was defined as $15 \%$ increase in FEV1/FVC after receiving tapering dose of prednisone $30 \mathrm{mg}$ for 2 weeks. None of the patients in case group showed increase in FEV1/FVC of $15 \%$. The change in pulmonary function tests were comparable in each group $(p>0.5)$. So, steroids in stable patients of COPD, are best to be avoided.

The major limitations in use of steroids in stable COPD patients were development of steroid related adverse effects. Smoking appeared to be the major risk factor for COPD.

\section{Funding: No funding sources}

Conflict of interest: None declared

Ethical approval: The study was approved by the Institutional Ethics Committee

\section{REFERENCES}

1. Halbert RJ, Natoli JL, Gano A, Badamgarav E, Buist AS, Mannino DM. Global burden of COPD: systematic review and meta-analysis. Eur Respir J. 2006;28(3):523-32.
2. American Thoracic Society: Standards for the diagnosis and care of patients with chronic obstructive pulmonary disease and asthma. Am Rev Respir Dis. 1987;36:225-8.

3. Harrison's Principles of Internal Medicine. 18th edition. McGraw Hill Education; 2011: 1491-1499.

4. CIBA Guest symposium: Terminology, dysfunction and classification of chronic pulmonary emphysema and related conditions thorax. Thorax. 1959;4:286.

5. Fletcher $\mathrm{C}$, Peto R. The natural history of chronic airflow obstruction. Br Med J. 1977;1:1645-8.

6. Sridhar M, Taylor R, Dawson S, Roberts NJ, Partridge MR. A nurse led intermediate care package in patients who have been hospitalised with an acute exacerbation of chronic obstructive pulmonary disease. Thorax. 2008;63(3):194-200.

7. Lynne Reid .Measurement of the bronchial mucous gland layer a diagnostic yard stick in chronic bronchitis. Thorax. 1960;15:132-41.

8. Hossain S, Heard B. Hyperplasia of bronchial muscle in chronic bronchitis. 1970;101:171-84.

9. Effing T, Kerstjens H, van der Valk P, Zielhuis G, van der Palen J. Cost-effectiveness of self-treatment of exacerbations on the severity of exacerbations in patients with COPD: the COPE II study. Thorax. 2009;64(11):956-962.

10. Segal MS, Dulfano MJ. Chronic Pulmonary Emphysema: Physiopathology and treatment. New York: Grune; 1953: 107-112.

11. Lowell FC, Franklin W Michelson A, Schiller W. Chronic obstructive pulmonary emphysema: disease of smokers. Ann Int Med. 1956;45:268-74.

12. Costo M, Ghezzo H, Hogg JC, Corbin R, Loveland M, Dosman J, et al. The relations between structural changes in small airways and pulmonary function test. New England J Med. 1978;298:1277-81.

13. American Thoracic Society. Lung function testing selection of reference values and interpretative strategies. American review of respiratory diseases. 1991;144:1202-18.

14. Gevardo S, Pedro S, Ronald B, George MD. Current pulmonology and critical care medicine. Internal Med. 1980;17:181-200.

15. Millard J, Filler JC. The treatment of chronic bronchitis. Geriatrics. 1965;20: 854.

16. Andrews AH, Coogan TJ. Office management of chronic obstructive emphysema and related conditions. Med Clin N Amer. 1958;92:155.

17. Beerel F, Jick H, Tyler JM. A controlled study of the effect of prednisone on air flow obstruction in severe pulmonary emphysema. New Eng J Med. 1963;226:68.

18. Fan VS, Gaziano JM, Lew R, Bourbeau J, Adams $\mathrm{SG}$, Leatherman $\mathrm{S}$, et al. A comprehensive care management program to prevent chronic obstructive pulmonary disease hospitalizations: a randomized, controlled trial. Ann Intern Med. 2012;156(10):67383. 
19. Chang S, Henry W. Response to corticosteroid in chronic bronchitis. J Allergy Clin Immunol. 1978;62:363-7.

20. Sahn SA. Corticosteroids in Chronic bronchitis and Pulmonary emphysema. Chest. 1987;73:389-96.

21. Dujoune CA, Azarnoff DL. Clinical complications of corticosteroid therapy: A selected review. Med Clin North Am. 1973;57:1331-42.
22. Cullen JH, Reidt WH. American review of respiratory diseases.1960;82:508.

Cite this article as: Khan $\mathrm{AH}$, Majeed M. Chronic obstructive pulmonary disease patients and steroids: benefit or harm. Int J Basic Clin Pharmacol 2019;8:2247-53. 